\title{
High-Dose Testosterone Propionate Treatment Reverses the Effects of Endurance Training on Myocardial Antioxidant Defenses in Adolescent Male Rats
}

\author{
Ewa Sadowska-Krępa • Barbara Kłapcińska • Sławomir Jagsz • Andrzej Sobczak • \\ Stanisław J. Chrapusta • Małgorzata Chalimoniuk • Paweł Grieb • \\ Stanisław Poprzęcki • Józef Langfort
}

Published online: 12 February 2011

(c) The Author(s) 2011. This article is published with open access at Springerlink.com

\begin{abstract}
This study was aimed at evaluation of changes in activities of selected antioxidant enzymes (superoxide dismutase, catalase, glutathione peroxidase, and glutathione reductase) and contents of key nonenzymatic antioxidants (glutathione, protein thiol groups, and $\alpha$ - and $\gamma$-tocopherols) in the left heart ventricle of young male Wistar rats subjected to endurance training (treadmill running, $1 \mathrm{~h}$ daily, 5 days a week, for 6 weeks) or/and testosterone propionate treatment ( 8 or $80 \mathrm{mg} / \mathrm{kg}$ body weight, intramuscularly, once a week, for 6 weeks) during adolescence. The training alone increased the activities of key antioxidant enzymes, but lowered the pool of nonenzymatic antioxidants and enhanced myocardial oxidative stress as evidenced by elevation of the lipid peroxidation biomarker malondialdehyde. The lower-dose testosterone treatment showed mixed effects on the individual components of the antioxidant defense system, but markedly enhanced lipid peroxidation. The higher-dose testosterone treatment decreased the activities
\end{abstract}

E. Sadowska-Krępa · B. Kłapcińska $(\bowtie) \cdot$ S. Jagsz ·

S. Poprzęcki · J. Langfort

Department of Physiological and Medical Sciences, Academy of Physical Education, 72A Mikołowska St., 40-065 Katowice, Poland

e-mail: b.klapcinska@awf.katowice.pl

\section{A. Sobczak}

Department of General and Inorganic Chemistry, Medical University of Silesia, School of Pharmacy, Sosnowiec, Poland

S. J. Chrapusta $\cdot$ P. Grieb · J. Langfort

Department of Experimental Pharmacology, Mossakowski

Medical Research Center, Polish Academy of Sciences, Warsaw,

Poland

M. Chalimoniuk

Department of Cellular Signaling, Mossakowski Medical

Research Center, Polish Academy of Sciences, Warsaw, Poland of the antioxidant enzymes, lowered the contents of the nonenzymatic antioxidants, except for that of $\gamma$-tocopherol, reversed the effect of endurance training on the antioxidant enzymes activities, and enhanced lipid peroxidation more than the lower-dose treatment. These data demonstrate the potential risk to cardiac health from exogenous androgen use, either alone or in combination with endurance training, in adolescents.

Keywords Adolescence - Antioxidant enzymes · Endurance training - Heart - Nonenzymatic antioxidants . Oxidative stress $\cdot$ Testosterone $\cdot$ Tocopherols

\section{Introduction}

The heart is characterized by one of the highest resting oxygen consumption rates among all body organs. High myocardial oxygen consumption, which is elevated in response to exercise [1], may result in enhanced production of reactive oxygen species (ROS) and impairment of the oxidant-antioxidant balance [2]. Indeed, increased generation of ROS is detectable in rat myocardium during acute exercise [3]. The excess ROS are disposed of quickly by the cellular antioxidant defense systems consisted of a number of antioxidant enzymes, including (but not limited to) superoxide dismutase (SOD; EC 1.15.1.1), catalase (CAT; EC 1.11.1.6), glutathione peroxidase (GPX; EC 1.11.1.9), and glutathione reductase (GR; EC 1.6.4.2), and nonenzymatic antioxidants, such as reduced glutathione (GSH) and $\alpha$ - and $\gamma$-tocopherols. Electrically induced tachycardia, which imitates cardiac effects of exercise, acutely decreases the activities of the antioxidant enzymes in the left heart ventricle (LV) in the rat [4], whereas the reports on the effects of exercise training on enzymatic and 
nonenzymatic antioxidant heart systems are equivocal [5-7]. Notably, there is no data on such effects in adolescents.

Myocardium is a sex steroid-sensitive tissue in that it expresses receptors for both androgens and estrogens $[8,9]$. Some studies suggest that abuse of androgenic steroids causes adverse cardiovascular effects (e.g. LV hypertrophy, hypertension, diastolic dysfunction, and cardiac failure) $[8,10,11]$. However, other reports suggest that testosterone improves myocardial lipid metabolism [12] and may act as a cardioprotectant and coronary vasodilator with effects comparable to those of conventional antiischemic drugs [13, 14]. It is also not clear whether androgens improve or worsen heart antioxidant status. For instance, androgens decrease activities of heart antioxidant enzymes in adult male rats [15]. On the other hand, orchidectomy markedly decreases LV activities of antioxidant enzymes in the rat $[14,16]$, while testosterone replacement reverses the deficit in tissue antioxidant capacity and substantially improves the recovery of cardiac work after ischemia/reperfusion in vitro [14].

Whereas exercise training is often combined with anabolic-androgenic steroid (AAS) use in real life (see [10, 11, 17-19]), attempts to dissect the response of the myocardial antioxidant system to such combination have not given clear-cut results. Moreover, there is no data on such effects in adolescents, in whom these phenomena may be affected by the ongoing somatic growth and the stilldeveloping pattern of sex steroids' production and secretion. Importantly, adolescence is the period that associates with increased interest of young people, particularly boys, in strength and/or endurance sports, or simply in bodybuilding. Their wish to succeed in such activities is often fulfilled by combined use of the most appropriate physical training and illegal use/abuse of AAS [10, 18, 19]. The aim of this study was to analyze the effects of endurance training and chronic androgen treatment of adolescent male Wistar rats on the capacity of both enzymatic and nonenzymatic antioxidant defense systems in the LV.

\section{Materials and Methods}

Animals

Adolescent (5-6 weeks old) male Wistar rats of 100-120 g body weight (BW), from the stock of Mossakowski Medical Research Center (Warsaw, Poland), were used for the study. The rats were housed four to five per cage, at 12-h light/12-h dark cycle (lights on at 7:00 a.m.), $22-24^{\circ} \mathrm{C}$ ambient temperature and $45-65 \%$ relative humidity, and were allowed standard pellet rat chow and tap water ad libitum. Before the start of the experiment, all rats were run-tested on a motorized rodent treadmill $(3 \times 5 \mathrm{~min}$, with 15-min breaks) for three successive days to habituate them to the training environment and to eliminate rats unwilling to run. The selected rats were randomized between the following groups: (1) untrained controls (UTr, $n=8$ ); (2) untrained rats receiving $8 \mathrm{mg} / \mathrm{kg}_{\mathrm{BW}}$ of testosterone propionate (TP) weekly (UTr + TP8, $n=8)$; (3) untrained rats receiving $80 \mathrm{mg} / \mathrm{kg}_{\mathrm{BW}}$ of $\mathrm{TP}$ weekly $(\mathrm{UTr}+\mathrm{TP} 80, n=8) ;(4)$ endurance-trained TP-untreated rats ( $\operatorname{Tr}, n=9$ ); (5) endurance-trained rats receiving $8 \mathrm{mg} /$ $\mathrm{kg}_{\mathrm{BW}}$ of TP weekly ( $\mathrm{Tr}+\mathrm{TP} 8, n=8$ ); and (6) endurancetrained animals receiving $80 \mathrm{mg} / \mathrm{kg}_{\mathrm{BW}}$ of $\mathrm{TP}$ weekly $(\operatorname{Tr}+\operatorname{TP} 80, n=9)$.

\section{Hormonal Treatment}

Stock TP solution (Testosteronum propionicum; Jelfa, Poland) was diluted with sesame oil as needed and injected intramuscularly once a week for 6 weeks, alternatingly into the right and left hindlimb. TP-untreated rats were given the same volume of the oil according to the same schedule. Our choice of the lower TP dosage used was based on the following facts: (1) a single TP dose of $8 \mathrm{mg} / \mathrm{kg}_{\mathrm{BW}}$ is sufficient to restore physiological levels of serum testosterone for about 1 week in castrated sedentary young adult male Wistar rats $[12,16]$, while it almost doubles circulating blood testosterone levels in their intact counterparts (Langfort et al., unpublished data), and (2) it approximated well the AAS dosage typically used by athletes/bodybuilders $[11,17,20]$. The higher TP dosage employed $\left(80 \mathrm{mg} / \mathrm{kg}_{\mathrm{BW}} /\right.$ week $)$ was chosen to roughly match the maximum reported AAS dosage [18]. The study protocol was approved by the First Warsaw Ethical Committee for Animal Experiments of the Polish Academy of Sciences, Warsaw, Poland (Certificate of approval No. 251).

\section{Endurance Training}

The rats scheduled for endurance training were exercised on a rodent treadmill (at $0^{\circ}$ inclination) 5 days a week, for 6 weeks. The treadmill speed was $16 \mathrm{~m} / \mathrm{min}$ during the first week, was increased by $4 \mathrm{~m} / \mathrm{min}$ weekly over the next 3 weeks, and was kept at $28 \mathrm{~m} / \mathrm{min}$ for the remaining training sessions. The session duration started each week at $40 \mathrm{~min} /$ day and was increased by $5 \mathrm{~min}$ daily during the first 4 weeks; during the last 2 weeks, the rats ran for $1 \mathrm{~h}$ daily. Two days after completion of the training, the rats were euthanized by decapitation. Trunk blood was collected, allowed to clot at room temperature, and spun to obtain serum for hormone assays. The chest was opened instantly, and the heart was perfused with the KrebsHenseleit buffer supplemented with glucose $(10 \mathrm{mM})$, immediately excised and weighed, and the LV was 
separated, weighed, and cut into pieces that were snapfrozen in liquid nitrogen and stored at $-80^{\circ} \mathrm{C}$ until analysis.

\section{Analytical Procedures}

LV samples were homogenized in ice-cold buffers according to the instructions provided by the manufacturer of diagnostic kits, or in ice-cold $0.1 \mathrm{M}$ phosphate-buffered saline $\mathrm{pH} 7.0(1: 5 \mathrm{w} / \mathrm{v})$, using an Ultra-Turrax $\mathrm{T} 8$ homogenizer (IKA Labortechnik, Staufen, Germany). The homogenates were either used immediately for the determination of reduced glutathione (GSH), $\alpha$ - and $\gamma$-tocopherols and malondialdehyde (MDA) or spun at $4,000 \times g\left(4^{\circ} \mathrm{C}\right)$ for $15 \mathrm{~min}$ to obtain supernatants for quantification of enzyme activities and protein thiols (-SH). CAT activity and the contents of tocopherols and protein thiols were assessed as described previously $[4,16]$. The activities of SOD, GPX and GR, and GSH content were measured using BIOXYTECH kits SOD-525, GPX-340, GR-340, and GSH-400 (OXIS International Inc., Portland, OR, USA) according to the manufacturer's instructions. Serum total testosterone (TT) was determined with a radioimmunoassay kit (Testosterone RIA, DSL-4100, Diagnostic System Laboratories Inc., Webster, TX, USA), and serum-free testosterone (FT) was measured using a coated-tube radioimmunoassay (KIPI19000, DIASource Immunoassays S.A., Belgium). Serum $17 \beta$-estradiol (E2) level was quantified using Elecsys Estradiol electrochemiluminescence kit (Roche, Mannheim, Germany). Total protein content was determined by the 2,2'-bicinchoninic acid method using Sigma Protein Assay Kit BCA1.

\section{Statistics}

All data are presented as means $\pm \mathrm{SD}$. A two-way ANOVA with endurance training and TP treatment as the main factors, followed, when appropriate, by the Tukey post hoc test, was used to test the significance of betweengroup differences. To assess possible associations between variables, Spearman's rank order correlation (except when specified otherwise) coefficients were calculated. In all cases, a $P<0.05$ was considered significant. All statistical analyses were performed using Statistica 7.1 software (StatSoft, Tulsa, OK, USA).

\section{Results}

Serum Sex Hormone Levels

TP treatment significantly and dose dependently elevated serum TT and FT levels both in sedentary (untrained) and in endurance-trained rats. Rats given the higher TP dose compared to the sedentary controls showed, irrespective of their training status, about 18 -fold and 44 -fold higher TT and FT levels, respectively. There was a strong positive correlation between TT and FT levels and a moderate correlation between TT and E2 levels. Two-way ANOVA revealed significant effects of TP treatment, no significant effect of endurance training, and significant training $\times \mathrm{TP}$ treatment interaction effects on TT and FT levels. E2 level was only marginally affected by the TP treatment and endurance training (Table 1).

\section{Body and Heart Weights}

Body weight was significantly lower in endurance-trained TP-untreated rats than in their sedentary counterparts and tended to be lower in animals receiving TP. Two-way ANOVA yielded significant effects of both endurance training and TP treatment and a significant interaction between these factors' effects on BW. Body weight showed significant negative correlation with serum TT level, whereas the correlation between heart weight (HW) and serum TT level did not reach significance. HW was significantly increased by TP treatment but not by endurance training. Heart-to-body weight ratio (HW/BW) positively correlated with serum TT and reached the highest level in the endurance-trained rats given the high-dose TP treatment (Table 1).

\section{Lipid Peroxidation}

Endurance training only moderately elevated LV MDA content, while TP treatment markedly elevated it both in trained and in sedentary rats at both doses employed. There was no significant interaction between these factors' effects on LV MDA content. Notably, there was a strong positive correlation between LV MDA content and serum TT level (see Table 1) and between LV MDA content and serum FT level $\left(R=0.74, P<10^{-6}\right)$.

\section{Left Ventricle Antioxidant Enzymes' Activities} and Nonenzymatic Antioxidants' Contents

SOD and CAT activities were significantly higher in the endurance-trained TP-untreated rats than in their sedentary counterparts; no similar differences were found between the respective GPX and GR activities. TP-treated rats, particularly those receiving the higher TP dose, showed markedly lowered activities of all antioxidant enzymes studied (Table 2). There was a strong negative correlation between SOD and CAT activity or serum FT $(R=-0.77$, $P<10^{-6}$ and $R=-0.63, P<10^{-5}$, respectively) and TT levels, whereas the correlations between GPX or GR activity and FT $\left(R=-0.63, P<10^{-4}\right.$, and $R=-0.54$, 


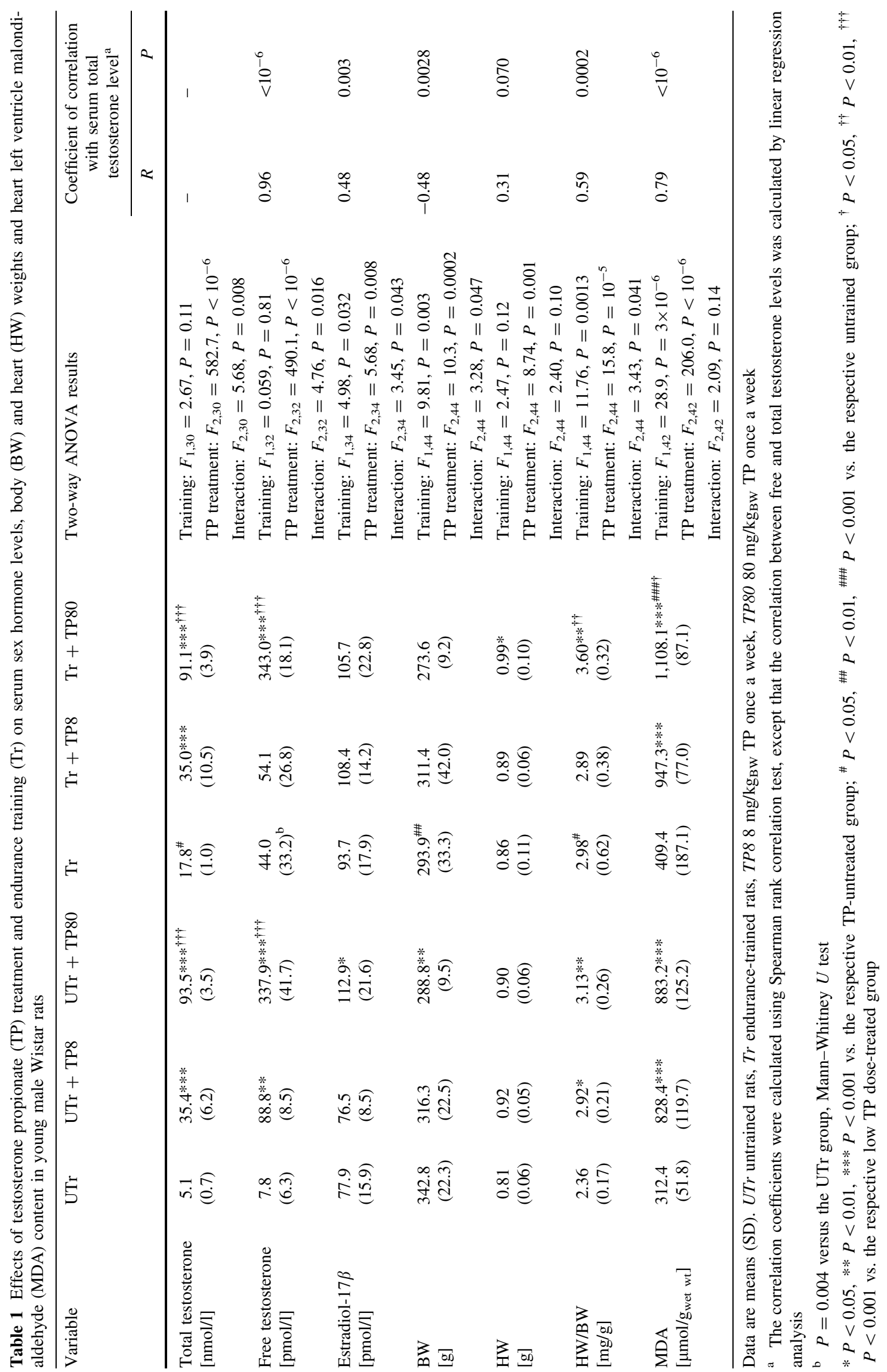




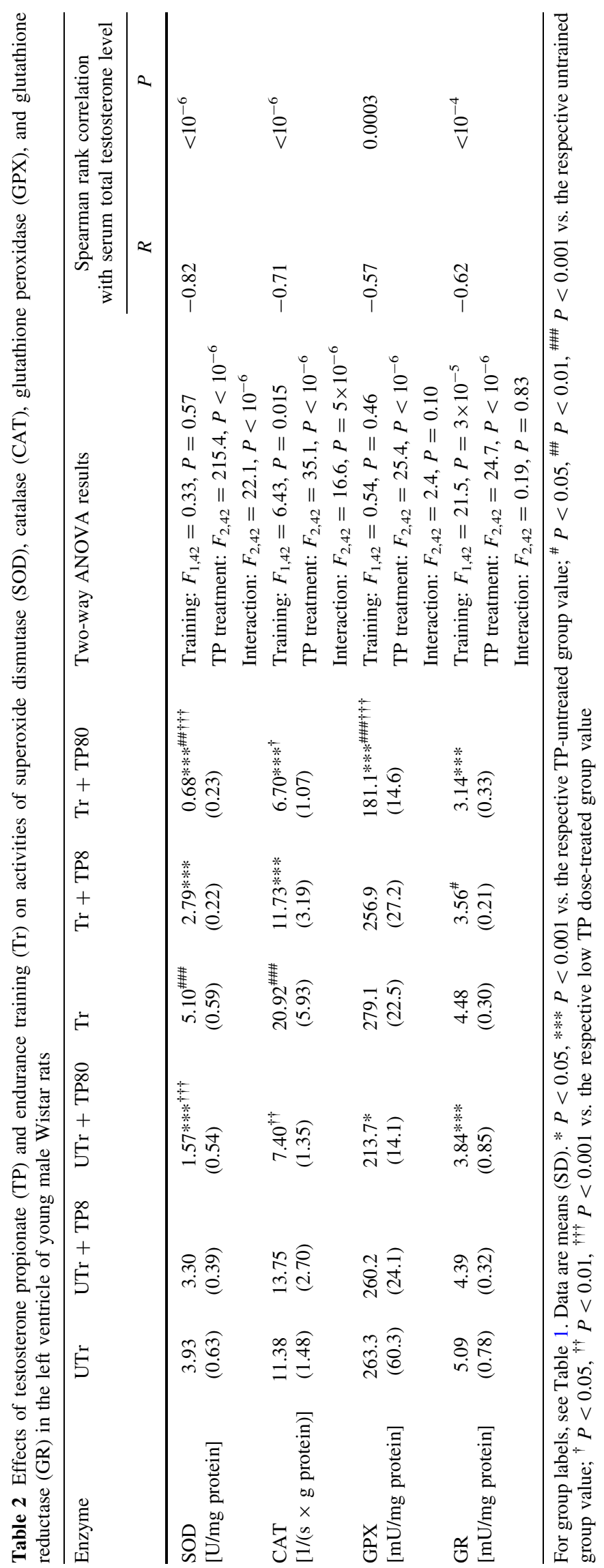




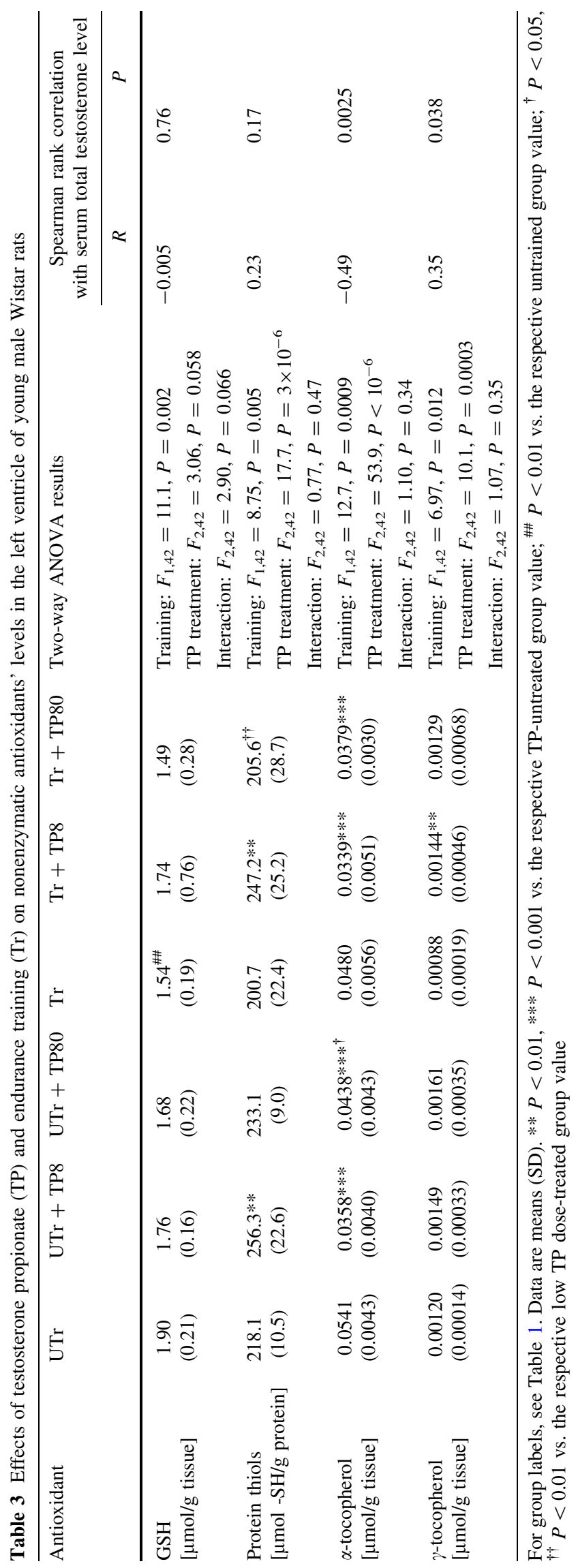


$P<10^{-3}$, respectively) or serum TT level (see Table 2) were somewhat weaker.

The endurance-trained rats compared to their untrained counterparts showed lower LV contents of all nonenzymatic antioxidants studied (Table 3). TP treatment resulted in significant decreases in the contents of $\alpha$-tocopherol and protein thiols; a marked tendency for such effect was also apparent in the LV GSH content. Notably, $\alpha$-tocopherol level correlated negatively with both serum FT (Spearman rank order correlation test: $R=-0.40, P=0.02$ ) and TT level. In contrast, $\gamma$-tocopherol content tended toward higher levels in both sedentary and trained groups of animals receiving TP and showed a significant, while moderate, positive correlation with serum TT level (see Table 3), but not with FT level $(P=0.13)$.

\section{Discussion}

The main findings of the present study are that (1) endurance training by itself increases the activity of two key components of heart enzymatic antioxidant system, namely SOD and CAT, but decreases the capacity of heart nonenzymatic antioxidant system and increases LV lipid peroxidation; (2) high-dose TP treatment decreases the capacity of both these antioxidant systems by itself, reverses the beneficial effect of endurance training on SOD and CAT activities, and potentiates myocardial lipid peroxidation. Whereas the effects of exercise training and androgens on heart antioxidant systems have been studied before, this study, to the best of our knowledge, is the first to investigate the effects of these factors in adolescent subjects. This issue is of considerable importance because of the well-known AAS abuse by adolescent bodybuilders and athletes and the emergence of the related spectrum of adverse side effects including a number of cardiac and cardiovascular complications leading eventually to death in some cases [10,11, 17, 19-22].

While AAS can cause detrimental shifts in serum lipid profile, AAS abuse-related cardiac deaths are not necessarily related to coronary thrombosis or atherosclerosis [10, $22,23]$, but may be caused also by a variety of pathological phenomena related to apoptosis [24]. The lower TP dose used in this study markedly elevated myocardial MDA in untrained rats, implying a substantial increase in oxidative stress. This may look surprising, as there was no concurrent decrease in major antioxidant enzyme activities and most nonenzymatic antioxidants studied. However, it is known that testosterone (serum levels of which positively correlated with LV MDA content in this study) elevates the activity of hormone-sensitive lipase and thereby stimulates lipolysis in rat cardiomyocytes [12]. This improves longchain fatty acids availability for ATP synthesis, which in turn elevates oxygen utilization and thus enhances generation of ROS. The reported testosterone-induced increase in adipose tissue lipolysis [25] could have contributed also to the decreased BW of TP-treated rats in this study.

TP treatment substantially elevated both serum TT and FT in our rats, but the respective relative increases were much larger for FT (see Table 1). The traditional view holds that only FT represents biologically active testosterone. However, there was a high positive correlation between serum TT and FT levels in this study, and the correlation coefficients between the other indices measured and FT or TT level were, pair wise, remarkably similar (not shown), except that there was no significant correlation between serum FT and E2 levels $(R=0.22, P=0.18)$. Thus, our data support the view that serum TT accurately reflects biologically active testosterone in adolescent rats $[10,26]$. Interestingly, serum TT levels in the rats treated with the lower TP dose were, 9 days after the last dose, several times higher than those found during the first week following the injection of the same TP dose to naïve young adult male rats (Langfort et al., unpublished data). This shows extensive buildup of serum testosterone with weekly TP doses, which is in clear contrast with the need for administration of TP at 2- to 3-day intervals in humans with the aim of attaining reasonably stable TT levels.

Evidence from animal studies indicates that, compared with other aerobic tissues, the heart has moderate levels of antioxidant enzymes and thus rather limited ability to remove ROS [2]. Hence, it is possible that the LV antioxidant enzyme system was unable to inactivate the excessive ROS formation consequential to supraphysiological testosterone doses used in our study. However, significant decreases in the antioxidant enzymes' activities could have contributed to increased oxidative stress in rats given the higher TP dose treatment. It is well documented that SOD is irreversibly inactivated (by up to 50\%) by its product hydrogen peroxide in a concentration-dependent manner [27]. Besides, CAT, a heme enzyme, is rapidly inhibited by superoxide anions $\left(\mathrm{O}_{2}^{\bullet^{-}}\right)$due to a reversible reaction of $\mathrm{O}_{2}^{--}$radicals with native enzyme which involves a reduction of the ferric $\left(\mathrm{Fe}^{3+}\right)$ center to oxyferrous heme $\left(\mathrm{Fe}^{2+}\right) \cdots \mathrm{O}_{2}$ [28]. Whereas consequences of increased oxidative stress in the model used in our study are not clear, it has been shown that such stress can induce apoptosis in rat ventricular myocytes in vitro [29]. Endurance training employing a protocol closely related to this used in our study has been shown to attenuate this effect by SOD- and Hsp70-mediated pathways in rats [30]. However, superoxide radical is not the only ROS that is involved in apoptosis, and different ROS may use distinct apoptotic pathways [29].

Our training protocol is known to shift anaerobic threshold to higher exercise intensity [31], and its 
effectiveness is additionally evidenced by the significant increase in $\mathrm{HW} / \mathrm{BW}$ ratio in TP-untreated endurancetrained rats in this study. The shift in anaerobic threshold is associated with increased oxidative capacity and reliance of oxidative muscles on fat metabolism and presumably with enhanced ROS formation that may lead to enhanced lipid peroxidation [32].

The published reports on changes in lipid peroxidation induced by chronic exercise are equivocal. For instance, significant increases in MDA content in heart tissue of chronically exercised rats were reported by some researchers [33], whereas no changes were found in another study [3]. Similarly, the literature is ambiguous regarding which myocardial antioxidants are elevated after exercise training [7, 15, 34, 35]. Endurance training has been shown to increase the activities of antioxidant enzymes, particularly of SOD and CAT, in adult rats. The most robust responses to endurance training revealed in the present study were the increases in LV activities of SOD (the enzyme considered essential for protection against ROS) and CAT (the enzyme involved in removal of hydrogen peroxide produced by SOD) in TP-untreated rats. This apparent enhancement of enzymatic antioxidant defense was, however, associated with a significant negative impact of the training on all nonenzymatic antioxidants studied, and thus it could not prevent the enhancement of lipid peroxidation evidenced by the significant effect of the training on LV MDA content. Again, this observation is in agreement with the aforementioned moderate ability of heart antioxidant systems for neutralizing ROS [2].

Two-way ANOVA of enzyme activities' data revealed significant interactions between endurance training and TP treatment effects on key components of the enzymatic antioxidant defenses, i.e., the SOD and CAT activities. This indicates that combining endurance training with the intake of high androgen doses in adolescent subjects weakens heart antioxidant defenses and may potentiate risk to cardiac health. On the other hand, there was no statistically significant interaction between endurance training and TP treatment effects on either the LV MDA or LV nonenzymatic antioxidants' levels. This result shows additivity of these manipulations and suggests no benefit, in terms of cardioprotection, from endurance training when combined with AAS use. In line with our observations, it has been shown that nandrolone decanoate treatment interferes with cardiac renin-angiotensin system and impairs the beneficial effect of another type of aerobic training (swimming) in young adult rats [36].

The heart is a target organ for estrogens that are supposed to be cardioprotective [37]. As suggested by positive, while moderate, correlation between serum testosterone and estradiol levels, a fraction of the injected TP was converted to estradiol in our rats. However, serum E2 level was but marginally affected by the TP treatment (see Table 1) and did not positively correlate with any studied component of the LV antioxidant defense system. Conversely, it showed significant negative correlations with $\mathrm{LV}$ SOD, CAT and GR activities, and with LV $\alpha$-tocopherol level, with correlation coefficients ranging from -0.32 to -0.45 . All these coefficients were considerably lower than those for serum TT level (see Table 2), which indicates that they merely reflected substrate-product relationship between testosterone and E2. These data are in agreement with earlier reports that showed no major effect of exogenous testosterone on circulating E2 level in male rodents [14] and suggest no cardioprotective effect from systemic testosterone aromatization.

Notably, there was no significant correlation between serum E2 level and LV $\gamma$-tocopherol content, whereas the latter correlated positively with serum TT level. ANOVA yielded significant decreasing effect on this antioxidant from endurance training and an opposing effect from TP treatment. The latter finding may be of importance in light of reports showing that $\gamma$-tocopherol has potent antiinflammatory properties [38] and may be an effective cardioprotectant [39]. It is not clear whether the elevation in LV $\gamma$-tocopherol was driven by its mobilization from peripheral stores in response to oxidant attack, as previously reported for other localizations [40, 41], or resulted from the known inverse relationship between $\gamma$ - and $\alpha$ tocopherol [42]. However, the substantial TP treatmentrelated elevation in LV MDA observed in the present study indicated that the increased $\gamma$-tocopherol content was insufficient to counteract the enhancement of myocardial oxidative stress induced by TP treatment.

To summarize, this study shows that in adolescent male rats: (1) all potentially beneficial effects of endurance training on the enzymatic components of the antioxidant defense system in the heart left ventricle are reversed by chronic high-dose testosterone propionate treatment and (2) none of the potentially detrimental effects of the training on the left ventricular antioxidant barrier are considerably counteracted by this treatment. These results imply that anabolic androgen use among adolescents, either alone or in combination with endurance training, may elevate oxidative stress-related risk to cardiac health.

Acknowledgments This study was supported by grant 6P05A-08621 from the State Committee for Scientific Research (Warsaw, Poland) and by statutory funds from the Academy of Physical Education (Katowice, Poland).

Conflict of interest The authors have no financial and/or personal relationships with other people or organizations that could influence this report.

Open Access This article is distributed under the terms of the Creative Commons Attribution Noncommercial License which 
permits any noncommercial use, distribution, and reproduction in any medium, provided the original author(s) and source are credited.

\section{References}

1. Duncker, D. J., \& Bache, R. J. (2008). Regulation of coronary blood flow during exercise. Physiological Reviews, 88, 1009-1086.

2. Ji, L. L. (2000). Exercise-induced oxidative stress in the heart. In C. K. Sen, L. Packer, \& O. Hänninen (Eds.), Handbook of oxidants and antioxidants in exercise (pp. 689-711). Amsterdam: Elsevier B.V.

3. Bejma, J., Ramires, P., \& Ji, L. L. (2000). Free radical generation and oxidative stress with ageing and exercise: Differential effects in the myocardium and liver. Acta Physiologica Scandinavica, $169,343-351$.

4. Kłapcińska, B., Sadowska-Krępa, E., Jagsz, S., Sobczak, A., Żendzian-Piotrowska, M., Górski, J., et al. (2009). Short-term effects of electrically induced tachycardia on antioxidant defenses in the normal and hypertrophied rat left ventricle. Journal of Physiological Sciences, 59, 199-206.

5. Morán, M., Delgado, J., González, B., Manso, R., \& Megías, A. (2004). Responses of rat myocardial antioxidant defences and heat shock protein HSP72 induced by 12 and 24-week treadmill training. Acta Physiologica Scandinavica, 180, 157-166.

6. Gul, M., Demircan, B., Taysi, S., Oztasan, N., Gumustekin, K., Siktar, E., et al. (2006). Effects of endurance training and acute exhaustive exercise on antioxidant defense mechanisms in rat heart. Comparative Biochemistry and Physiology. Part A, Molecular \& Integrative Physiology, 143, 239-245.

7. Ahmadiasl, N., Soufi, F. G., Alipour, M., Bonyadi, M., Sheikzadeh, F., Vatankhah, A., et al. (2007). Effects of age increment and 36-week exercise training on antioxidant enzymes and apoptosis in rat heart tissue. Journal of Sports Science and Medicine, 6, 243-249.

8. Weidemann, W., \& Hanke, H. (2002). Cardiovascular effects of androgens. Cardiovascular Drug Reviews, 20, 175-198.

9. Marsh, J. D., Lehmann, M. H., Ritchie, R. H., Gwathmey, J. K., Green, G. E., \& Schiebinger, R. J. (1998). Androgen receptors mediate hypertrophy in cardiac myocytes. Circulation, 98, 256-261.

10. Hoffman, J. R., Kraemer, W. J., Bhasin, S., Storer, T., Ratamess, N. A., Haff, G. G., Willoughby, D. S., Rogol, A. D. (2009). Position stand on androgen and human growth hormone use. Journal of Strength and Conditioning Research, 23(5 Suppl), S1S59.

11. Hartgens, F., \& Kuipers, H. (2004). Effects of androgenic-anabolic steroids in athletes. Sports Medicine, 34, 513-554.

12. Langfort, J., Jagsz, S., Dobrzyn, P., Brzezinska, Z., Klapcinska, B., Galbo, H., et al. (2010). Testosterone affects hormone-sensitive lipase (HSL) activity and lipid metabolism in the left ventricle. Biochemical and Biophysical Research Communications, 399, 670-676.

13. Liu, J., Tsang, S., \& Wong, T. M. (2006). Testosterone is required for delayed cardioprotection and enhanced heat shock protein 70 expression induced by preconditioning. Endocrinology, 147, 4569-4577.

14. Borst, S. E., Quindry, J. C., Yarrow, J. F., Conover, C. F., \& Powers, S. K. (2010). Testosterone administration induces protection against global myocardial ischemia. Hormone and Metabolic Research, 42, 122-129.

15. Chaves, E. A., Pereira-Junior, P. P., Fortunato, R. S., Masuda, M. O., Campos de Carvalho, A. C., Pires de Carvalho, D., et al.
(2006). Nandrolone decanoate impairs exercise-induced cardioprotection: Role of antioxidant enzymes. Journal of Steroid Biochemistry and Molecular Biology, 99, 223-230.

16. Kłapcińska, B., Jagsz, S., Sadowska-Krępa, E., Górski, J., Kempa, K., \& Langfort, J. (2008). Effects of castration and testosterone replacement on the antioxidant defense system in the rat left ventricle. Journal of Physiological Sciences, 58, 173-177.

17. Graham, M. R., Davies, B., Grace, F. M., Kicman, A., \& Baker, J. S. (2008). Anabolic steroid use. Patterns of use and detection of doping. Sports Medicine, 38, 505-525.

18. Kanayama, G., Hudson, J. O., \& Pope, H. G., Jr. (2008). Longterm psychiatric and medical consequences of anabolic-androgenic steroid abuse: A looming public health concern? Drug and Alcohol Dependence, 98, 1-12.

19. Bahrke, M. S., Yesalis, C. E., Kopstein, A. N., \& Stephens, J. A. (2000). Risk factors associated with anabolic-androgenic steroid use among adolescents. Sports Medicine, 29, 397-405.

20. Achar, S., Rostamian, A., \& Narayan, S. M. (2010). Cardiac and metabolic effects of anabolic-androgenic steroid abuse on lipids, blood pressure, left ventricular dimensions, and rhythm. American Journal of Cardiology, 106, 893-901.

21. Sculthorpe, N., Grace, F., Jones, P., \& Davies, B. (2010). Evidence of altered cardiac electrophysiology following prolonged androgenic anabolic steroid use. Cardiovascular Toxicology, 10, 239-243.

22. Maron, B., Roberts, W. C., McAllister, H. A., Rosing, D. R., \& Epstein, S. E. (1980). Sudden death in young athletes. Circulation, 62, 218-229.

23. Fanton, L., Belhani, D., Vaillant, F., Tabib, A., Gomez, L., Descotes, J., et al. (2009). Heart lesions associated with anabolic steroid abuse: Comparison of post-mortem findings in athletes and norethandrolone-induced lesions in rabbits. Experimental and Toxicologic Pathology, 61, 317-323.

24. Zaugg, M., Jamali, N. Z., Lucchinetti, E., Xu, W., Alam, M., Shafiq, S. A., et al. (2001). Anabolic-androgenic steroids induce apoptotic cell death in adult rat ventricular myocytes. Journal of Cellular Physiology, 187, 90-95.

25. Mayes, J. S., \& Watson, G. H. (2004). Direct effects of sex steroid hormones on adipose tissues and obesity. Obesity Reviews, 5, 197-216.

26. Nazian, S. J. (1986). Concentrations of free testosterone, total testosterone, and androgen binding protein in the peripheral serum of male rats during sexual maturation. Journal of Andrology, 7, 49-54.

27. Salo, D. C., Pacifici, R. E., Lin, S. W., Giulivi, C., \& Davies, K. J. A. (1990). Superoxide dismutase undergoes proteolysis and fragmentation following oxidative modification and inactivation. Journal of Biological Chemistry, 265, 11919-11927.

28. Kono, Y., \& Fridovich, I. (1982). Superoxide radical inhibits catalase. Journal of Biological Chemistry, 257, 5751-5754.

29. von Harsdorf, R., Li, P. F., \& Dietz, R. (1999). Signaling pathways in reactive oxygen species-induced cardiomyocyte apoptosis. Circulation, 99, 2934-2941.

30. Siu, P. M., Bryner, R. W., Martyn, J. K., \& Alway, S. E. (2004). Apoptotic adaptations from exercise training in skeletal and cardiac muscles. FASEB Journal, 18, 1150-1152.

31. Langfort, J., Barańczuk, E., Pawlak, D., Chalimoniuk, M., Lukacova, N., Marsala, J., et al. (2006). The effect of endurance training on regional serotonin metabolism in the brain during early stage of detraining period in the female rat. Cellular and Molecular Neurobiology, 26, 1327-1342.

32. Halliwell, B., \& Gutteridge, J. M. C. (2007). Free radicals in biology and medicine, 4th edn. Oxford: Oxford University Press. ISBN 019856869X.

33. Liu, J., Yeo, H. C., Övervik-Douki, E., Hagen, T., Doniger, S. J., Chyu, D. W., et al. (2000). Chronically and acutely exercised 
rats: Biomarkers of oxidative stress and endogenous antioxidants. Journal of Applied Physiology, 89, 21-28.

34. Powers, S. K., Quindry, J. C., \& Kavazis, A. N. (2008). Exercise-induced cardioprotection against myocardial ischemiareperfusion injury. Free Radical Biology and Medicine, 44, 193-201.

35. Hamilton, K. L., Staib, J. L., Phillips, T., Hess, A., Lennon, S. L., \& Powers, S. K. (2003). Exercise, antioxidants, and HSP72: Protection against myocardial ischemia/reperfusion. Free Radical Biology and Medicine, 34, 800-809.

36. Rocha, F. L., Carmo, E. C., Roque, F. R., Hashimoto, N. Y., Rossoni, L. V., Frimm, C., et al. (2007). Anabolic steroids induce cardiac renin-angiotensin system and impair the beneficial effects of aerobic training in rats. American Journal of Physiology-Heart and Circulatory Physiology, 293, H3575-H3583.

37. Czubryt, M. P., Espira, L., Lamoureux, L., \& Abrenica, B. (2006). The role of sex in cardiac function and disease. Canadian Journal of Physiology and Pharmacology, 84, 93-109.
38. Jiang, Q., \& Ames, B. N. (2003). $\gamma$-Tocopherol, but not $\alpha$ tocopherol, decreases proinflammatory eicosanoids and inflammation damage in rats. FASEB Journal, 17, 816-822.

39. Ohrvall, M., Sundlof, G., \& Vessby, B. (1996). Gamma, but not alpha, tocopherol levels in serum are reduced in coronary heart disease patients. Journal of Internal Medicine, 239, 111-117.

40. Elsayed, N. M. (2001). Antioxidant mobilization in response to oxidative stress: A dynamic environmental-nutritional interaction. Nutrition, 17, 828-834.

41. Palace, V. P., Hill, M. F., Farahmand, F., \& Singal, P. K. (1999). Mobilization of antioxidant vitamin pools and hemodynamic function after myocardial infarction. Circulation, 99, 121-126.

42. Christen, S., Woodall, A. A., Shigenaga, M. K., Southwell-Keely, P. T., Duncan, M. W., \& Ames, B. N. (1997). $\gamma$-Tocopherol traps mutagenic electrophiles such as $\mathrm{NO}(\mathrm{X})$ and complements $\alpha$ tocopherol: Physiological implications. Proceedings of the National Academy of Sciences of the United States of America, 94, 3217-3222. 